\title{
A Comparative Study of the Pedagogy of Learner- centred Education in Bangladesh and China: Implications of Policy Borrowing
}

\author{
Arif Ahmed Zufi* \\ Assistant Professor of English, Govt. M. R. Women's College, Bogra, Bangladesh \\ *Corresponding author: zufilabid@yahoo.com
}

\begin{abstract}
Educational reforms around the countries are a crucial issue in international and comparative education. Almost every country in the Global South is in search of an education policy which is benchmarked against other global educational policies of international standard. This quest engages them into policy borrowing. There are several other reasons for this educational transfer as well. This paper has attempted to explore the issues relating to policy borrowing of two countries Bangladesh and China. The case is selected because of its significance in international comparative education and implication is there also for the policy formulators concerned in both the countries. The study draws upon secondary sources literature such as existing literature, policy documents, reports of international organisations etc. A descriptive analysis has been attempted in order to achieve a better view of the issues under investigation. The results affirmed a similar model of policy transfer in both Bangladesh and China. In both cases the educational policy transplantation has proved to be a failure.
\end{abstract}

Keywords: Learner-centred Pedagogy, education policy borrowing, Bangladesh, China

Cite This Article: Arif Ahmed Zufi, "A Comparative Study of the Pedagogy of Learner-centred Education in Bangladesh and China: Implications of Policy Borrowing." American Journal of Educational Research, vol. 6, no. 1 (2018): 70-75. doi: 10.12691/education-6-1-11.

\section{Introduction}

Educational change across the countries of the world is portrayed as a quest to generate world class schools through the transfer of features of high performing school systems. The demand for evidence to support policy borrowing has been serviced by an influential intermediary network, which uses international data bank to compare education systems and to identify and promote evidence of 'what works' [1]. Although the learning process is a matter of 'cognitive physiology' [2], which is very complex in its general manifestations to the laypersons, its overriding influential pervasiveness has been a recurrent theme for the international and comparative education researchers for the last few decades. Academicians belonging to the paradigm of international and comparative education or related ones throughout the world are now considering the issue of learning process not only in the short and limited context of classroom or institution but also in a fairly larger or broader landscape of culture and policy formulation. In this article, the aspects of educational policy borrowing process, and the gap between policy and practice in Bangladesh and China have been compared and evaluated in the light of Learnercentred Education under a globalised worldview. It is a 'sound and viable choice for policy and practice in the developing world' [2]. Since the importance of literacy and numeracy as the component of 'human capital'
(Mincer: 1958 cited in Colclough, 2012 [3]) is immense, research evidence shows that Learner-centred classroom yields far more highly than the teacher-centred or rote learning-based classroom (Ibid: 62). Besides, research evidence from practical realities also shows that Learnercentred Education is really worthy of investigation from its assumed remedial roles to fight dropouts and school refusal. Moreover, Colclough [3] tries to measure the impact of education on development which renders the subject with a renewed significance both nationally and internationally, and specially in the developing country perspective.

Bangladesh and China, two Asian countries, have been chosen because both the countries have some commonalities in their geo-political or socio-cultural and economic aspects. According to World Economic League table 2016 (Data source: IMF World Economic Outlook, April, 2016), China is the largest economy (GDP based on PPP valuation) in the world. But if we consider Real GDP Growth rate, China (6.9) is not very far ahead of Bangladesh (6.4). Moreover, According to World Economic Forum Human Capital Report 2015, Bangladesh and China have been indexed at a close distance with score of 57.62 and 67.47 respectively out of the total score 100 . Both are considered as middle income countries overburdened with huge population. But China's recent exponential economic development along with high scores on international tests of achievement, have brought its education system, policy and practices to light. So this sort of comparative evaluation might help the policy 
makers to formulate effective policies for the development of pedagogy in particular and human capital in general.

As to the research approach for the present study, a qualitative approach will be applied for data analysis. This study completely draws on secondary data gleaned from relevant literature and other sources.

This research paper's first section introduces the theme of Learner-centred Education, issues of investigation, rationale for the theme and choice of countries for comparison. The second section provides an overview of relevant literature on three aspects such as theme of LCE, international comparative education and comparative methods and education policy related issues in Bangladesh and China. In the third section, a comparative framework on policy borrowing is presented and the sources of data are enlisted. In the fourth section, analysis has been carried out drawing on literature concerned, data and practical experience. In the final section, some critical comments with pedagogic insight are provided.

\section{Arena of Comparative and International Education}

Comparative Education has a long history with its origins in the early years of the nineteenth century as the states in Europe and elsewhere were starting to build their national systems of education. Over the years, many have been concerned with whether comparative education is a discipline, a field of study, an approach or a method-a way of data collection. Most scholars would probably now agree that comparative education is a sub-field of Education Studies. Colclough (2010, cited in Marshall, 2014 [5]) comments that because of the vast range of topics within the field comparative education is not constrained by disciplinary boundaries. However, the study of education in increasingly globalised contexts inevitably draws us towards comparison. According to Phillips and Schweisfurth [6], comparative studies are 'usually (though not exclusively) international in nature, and international studies are implicitly comparative'. Phillips [7] shows that 'learning from the experience of others' would be one of the most significant purposes of comparative study of education. He continued:

Perhaps, indeed, this is the single most important purpose we can identify to justify- in practical terms- what comparativists do. The 'learning' involved might result in an effort to improve provision 'at home', but equally it might help us to understand more fully what it is that has helped to form the system of education of which we are a part. (297)

So it may be assumed that comparative education generally leads to a greater understanding of the process of education across national levels.

\section{Policy borrowing in a Global Context}

One of the prominent features of comparative studies in education seems to be the learning from other countries. In education the study of policy borrowing has helped to validate and legitimise the field of comparative education. However, learning from comparison does not necessarily mean that policies and practices should actually be transferred from one context to another. Eminent comparativists like Michael Sadler, Brian Holmes and Robert Cowen warned against analysing education out of context and against using comparison to transplant educational reforms from one country to another [8]. But in an era of globalisation transnational policy borrowing, whether rhetorically or factually, is the norm and not the exception. Thus the policy stream tends to be available to politicians and decision makers at all times in the form of 'best practices' or 'international standards' or lessons learned from other educational systems. In fact, the pressure to borrow is great to the extent that policy analysts are frequently placed in the awkward position of having to retroactively define the local problem that fits the already existing global solution or reform package [8]. Indeed, the analytical approach to the study of policy borrowing includes typically a political and an economic dimension. In its political manifestation 'international standards' have become an increasingly common point of reference in such decisions. Economically, policy borrowing is a transient phenomenon, because it only exists so long as external funding-- contingent upon the import of a particular reform package-continues. Policy borrowing in poor countries is to the education sector what structural adjustment, poverty alleviation and good governance, are to the public sector at large: a condition for gaining aid. Under the purview of coercive and unidirectional policy borrowing in developing countries reforms are always transferred from the Global North/West to the Global South/East.

\section{Learner-centred Education as a Global Policy}

Learner-centred education is a 'travelling policy' [2], widely promoted by international agencies and national governments and a sound choice for policy and practice in developing countries. Travelling policies are generally adopted across different sites shaped by the activity of supra-national and transnational agencies and by shared educational agendas (Ozga and Jones, 2006 cited in Schweisfurth, 2013 [2]). In this globalised world, the borrowing of policy across contexts is a valuable dimension of the contemporary policy landscape. LCE's transfer, translation and transformation (Cowen, 2009 cited in Schweisfurth, 2013 [2]) across the world certifies to the power of its cross-national attractiveness as pedagogy. Its global quality is also manifested in its relevance in international agreements promoted by international agencies around the globe. Educationists are eager to enjoy the drama of educational ideas and policy move in a 'globe' theatre. As Carney (2009, cited in Schweisfurth, 2013 [2]) notes:

Recent critiques of comparative education suggest that we must move beyond the study of bounded and stable education systems, levels and processes, and acknowledge the ways in which educational phenomena-from policy visions to practices-are increasingly interconnected. (63)

To what extent LCE is an appropriate policy choice in developing country contexts is a recurrent question which the international and comparative education researchers 
worldwide are plagued with. Because of the crystal clear gap between policy documents and real practice in these low and middle income countries these questions of blind transfer and adoption should be revisited. The tensions between the global and the local are particularly intense when they bring something as controversial and culturebound as pedagogy. For example, Russia and China, two middle income countries, draw international attention because of the significance of LCE in these policy contexts. Russian and Chinese contributions to this debate on LCE will definitely serve us food for thought.

\section{Education Policy in Bangladesh}

The whole education system itself is more than a problem in Bangladesh [9]. Although there as many as six education commissions have been constituted so far since its advent as an independent state in the globe, we have not got any sound education policy till 2010 . There was a clarion call to the need of reforms in the educational planning and policy formulation. Bangladesh is in quest of such a pragmatic education system that can meet the demand of the changing world in the new era of globalisation.

Although progress on education is sought mainly as an end in itself, there has been firm evidence that education promotes economic growth, and thus puts other goals of development within reach. An explicit emphasis on human development for turning the huge population of the country into an asset has also been a major policy objective of the Bangladesh Government. The overriding importance of the education sector in the development process is unquestionable and this renders the reforms or further reforms in the education policy formulation in Bangladesh as one of the most significant development issues which still pose a formidable challenge.

The important aspects of Bangladesh National Education Policy 2010 cover the emphasis on modern science and technology education, modernised and childcentred curriculum, remarkable achievement in MDGs, successful EFA (Education For All) programme (Preface to the National Education Policy 2010) for sustainable development to meet the challenge of globalisation. The issues of equity and social justice are also carefully addressed in the education policy as these values are grounded in the Bangladesh Constitution (see Article 17a, $17 b, 17 c, 28$ and 41).

\section{Education Policy in China}

China moves toward western education policies in the1980s emulating the United States (Niu, 2007 cited in Schweisfurth, 2013 [2]). The child-centredness is included in Chinese curriculum in 2001 (MoE, China, 2001) [10]. The new curriculum reforms the learning styles encouraging learners' participation in the exploration of knowledge and acquisition and process of new information. In 2010 China's Ministry of Education releases guidelines for education reform. In an open market economic atmosphere and significant shift towards a services and skills-based economy, the country's education system has become a high-priority area for the government (MoE China, 2010).

China's 'remarkable progress' [11] in poverty reduction or in other spheres is sometimes attributed to its tremendous educational progress. In post-2015 policy discourse, it is claimed that 'in respect of education China had made big progress by incorporating the MDGs into its long and medium-term national development strategy' (UNA, 2012:3 cited in King, 2014 [11])

The educational reforms in China in the past few decades have been aimed at changing the traditional 'difficult, complex, unbalanced and outdated' curriculum content and the over-emphasis on textbook knowledge, passive learning, rote-memorisation and drilling [10]. These reforms appear to be policies and practices borrowed from 'the West'. Major policy initiatives are decentralisation through greater school autonomy and school based curriculum, introduction of extra-curricular programmes and activities such as robotics, dance and field-trips, and endorsement of student-centred learning strategies and assessment such as group work, student presentations and project work [12].

\section{Methodological Approach}

Phillips and Ochs [13] framework has been exploited for unpacking the complex layers of policy borrowing in Bangladesh and China with the underpinnings of historical, political and cultural aspects. Phillips and Ochs [13] created a four-tier cyclic model based on the analysis of policy borrowing process internationally. The main stages are Cross-national attraction, Decision, Implementation, and Internalisation/Indigenisation. This framework describes four stages in the borrowing procedure, from the events and situations which spark off the initial 'crossnational attraction', through the decision-making procedures that led to the adoption of a certain policy and at the third stage, its implementation, and then to the 'internalisation' or 'indigenisation' of the policy within the 'home' system. This 'promising and revealing research area' [6], even if it falls short to be a method itself, will be helpful to provide sequential stages for an analysis and determine the significance of context in comparative research. It can be assumed that the application of this framework will assist us in exploring some driving forces behind educational policy import such as internal dissatisfaction, economic change and political change etc. and in understanding the conceptual framework of comparative and international education itself. The Bray and Thomas framework can be taken into account only for identifying three different aspects of comparison variables such as 'Countries', 'Teaching methods' and 'Entire population' (Ibid: 21). Ministry of Education of Bangladesh, MoEDU of China, World Bank, IMF, UNDP and UNESCO have been taken as the data sources for the investigation.

\section{Comparison and Evaluation}

The educational policies of Bangladesh and China have been compared using Phillips and Ochs [13] framework for policy borrowing. 


\subsection{Stage 1- Cross-National Attraction}

The first stage of the model is Cross-National Attraction which translates itself into 'impulses'. For example, systemic collapse (inadequacy of some aspect of educational provision), negative external evaluation (success in international test like PISA or TIMSS), economic change, political change, regional or local configurations like globalisation and various international alliances etc. might be considered as cross-national attractions. In the case of Bangladesh, the attraction includes the quest for a perfect global and knowledgebased educational atmosphere. Despite considerable investment of scarce resources in the education sector, the quality of education in Bangladesh deteriorated phenomenally [9]. But it is also an incontrovertible fact that in a world where knowledge and scholarship is benchmarked by global standards, there is no room for mediocrity. In Bangladesh, poverty is still widespread; people are global citizens and must be internationally competitive and must respond to the challenges of the new knowledge-based global society.

In the case of China, impulses for borrowing might be a philosophical paradigm shift in learning style from Confucian to western or international. Still the economic aspiration is not absent here. Because, although progressing quickly from economic perspective, China is burdened with both education inequality and income inequality $(29.5 \%$,) (UNDP 2014). There is discrimination between rural and urban areas in terms of education and standard of life.

\subsection{Stage 2- Decision}

The second stage of the framework is decision. Among all other types of descriptors of decision, the final or fourth descriptor 'quick fix' decision has been applied to Bangladesh. It is one of the most dangerous outcomes of the processes of cross-national attraction. A glaring instance can be South Africa's enthusiasm for 'outcomes based education' or OBE, an approach to teaching and learning which was controversial in 'countries with a much more stable base to their educational provision than South Africa had in the immediate post-apartheid period' [14]. In Bangladesh, policy formulators are strongly influenced by both 'internal and external' [9] factors. Internally, political forces which are at power try to shape their political ideology. With the change of the government the fundamental policies are also changed overnight without judging their worth. The reason is Bangladesh starts its democratic journey only two decades ago. The democratic culture is not observed properly anywhere in the government machinery. So, it can be assumed that education policy formulation is a kind of imposing from the government side. Again, externally the government is pressured upon by international donor agencies, NGOs, and foreign development associates about accomplishing many international agendas as part of their overdependence on foreign aid. So, 'quick fix' decisions like EFA, LCE, Unitrack Curriculum, Creative Methods in Examination or evaluation system etc., whether they are compatible with Bangladesh's cultural, historical, social or economic contexts or not are common in Bangladesh.

In China, the government has tight control over the country and all the spheres. It might decide that education is to be its policy priority. So the decision is theoretical.

\subsection{Stage 3- Implementation}

Simkins et al, (1992 cited in Phillips and Ochs, 2003 [14]) points out two major components for education reform: strong belief within government and consensus about possible solutions. The degree of adaptation depends on many contextual factors. Moreover, change might be quick or long-term in nature, depending on the adaptability of particular policy measures. Again, change will be influenced by 'significant actors' and their decisions at various stages and levels. 'Significant actors' might be bodies like local education authorities, school boards, or boards of governors, or they might be individuals like chief education officers, advisers and head teachers.

In the case of Bangladesh, the government might not have 'strong belief', rather they pretend to have belief about what is wrong. Very frequent changes of policies and principles on the part of the government support this assumption. As far as this researcher's own experience goes, 'Significant actors' do not carry out their respective jobs, as they are sometimes quite unaware of the government policy implications.

In China, the implementation process of education policy is much more vigorous than in Bangladesh. If we look at the UNDP Human Development Index 2014, China $\left(90^{\text {th }}\right.$, High Human Development) is far ahead of Bangladesh (142th, Medium Human Development). Moreover, recent PISA results (although it is not without criticism) are also indicative of China's great achievement in education.

\subsection{Stage 4- Internalisation/Indigenisation}

In the final stage of the framework, the borrowed policy becomes part of the system of education of the borrower country through four consecutive steps: impact on the existing system, absorption of external features or contextualisation, synthesis or re-contextualisation and evaluation.

In Bangladesh, the internalisation stage of policy borrowing remains very bleak. This might be due to the lack of contextualisation of foreign features in the domestic educational setting. Ochs and Phillips [15] show five forces of context. The complex significance of context, the 'embeddedness' of aspects of educational approaches and provision in the locally prevailing culture and other conditions has really been crucial to deal with in policy borrowing process.

Research literature shows that China also could not contextualise the foreign features of LCE. Quoting the opinions of Chinese educational scholar Li Bingde, Hayhoe notes: 'There has always been a lack of balance, a tendency to lean too far towards external solutions, and, as a result, an inability to absorb and adapt what was introduced from outside' (Hayhoe, 2006: 103, cited in Schweisfurth, 2013 [2]). 


\section{Policy-Practice Continuum in Bangladesh and China}

Both Bangladesh and China introduces LCE in their education policies. But there is a huge gap between policy and practice in Bangladesh. On the one hand, policy documents show that 'Teachers are oriented to use the facilitating mode and learner-centred participatory approach in conducting classes' (Section 8.13, EFA: National Plan of Action II-2003-2015, Govt. of Bangladesh, pp-75). National Education Policy 2010 (section 26, pp-15) also mentions an 'interactive teaching method' as teaching and learning style. In reality, the teaching and learning culture remains almost unchanged. Teachers cannot or do not carry out some pedagogical principles of LCE such as learner autonomy, pair work, group work etc. Moving towards LCE means less banking and more constructing of knowledge, less teacher lecturing and more individual or collaborative teaching and learning. An important aspect of LCE such as teacher -student relationship is not 'democratic', it is rather authoritarian in Bangladesh. The historical background of the country shows that obedience is the Asian value embedded in our learners [16]. Moreover, the researcher's own experience shows that teachers cannot bring democratic culture in learning and teaching practice for some practical reasons such as large class size and lack of proper training, limited basic qualification etc. These reasons are related to limited resource of the country. Government spending on education falls short as the number of students is very high. Another important cultural aspect is that although it is erroneous to be too sweeping in offering cultural generalisations (Elliot and Tudge, 2007: cited in Nguyen et al, 2009 [16]) it can rationally be assumed that most western cultures are associated with individualism whereas most Asian cultures are identified with collectivism. So, from the cultural point of view, LCE is not a successful policy borrowing for Bangladesh.

Understanding the place of LCE in Chinese education policy is really difficult because of its paradoxical nature. Policy documents affirm the move towards the direction of LCE, in response to internal pressures and national priorities, along with external influences. But practically we can observe the resilient layers of teaching and learning cultures, ranging from Confucian heritage to Marxist ideology to competitive examinations, which shape the degree and nature of LCE implementation [2]. Moreover, China is highly affected with educational inequality. Many of rural Chinese schools, and even urban schools for the migrants from rural areas suffer from under-resourcing.

Western 'best practice' has been a model at various times in the history of Chinese educational reform, particularly in the recent moves to LCE, and it is supported on the ground by the efforts of aid agencies and international NGOs. From cultural point of view, Chinese learners still belong to Confucianism. With their 'perception of a proper human order, grounded in values such as self-reliance, individual responsibility, (and) family cooperation' (Hayhoe, 2006, cited in Schweisfurth, 2013 [2]), enduring cultural forms- often but not always accurately, ascribed to Confucianism-have survived Marxism and modernist pressures. In this cultural perspective, China bears many similarities with Bangladesh.

\section{Concluding Remarks}

LCE has been a 'recurrent theme in many national educational policies' [17]. Learner-centred pedagogy as a policy discourse has been globally travelling prescriptions for improvements to teaching and learning. Although culture is not the 'only determinant of teaching and learning' [18] process, its significance can never be underestimated. Sternberg (2007 cited in Schweisfurth, 2013 [2]) uses the theory of 'successful intelligence' in arguing for a better understanding of learning in a different cultural contexts and shows that individuals in different cultures may think about concepts and problems in different ways. Moreover, understanding of cultural aspects plays a very crucial role in policy borrowing, as investigated in the cases of Bangladesh and China. Without a sound knowledge of intractable cultural settings of particular systems 'foreign' educational policies cannot be understood properly. Drawing on the above discussion, the importance of deeper understanding of various cultural facets in relation to pedagogy is of paramount importance in the domain of International and Comparative Education.

\section{References}

[1] Auld, E. and Morris, P. 2014. Comparative education, the 'New Paradigm' and policy borrowing: constructing knowledge for educational reform. Comparative Education. 50: 2. pp. 129-155.

[2] Schweisfurth, M. 2013. Learner-centred Education in International Perspective: Whose pedagogy for whose development?. London: Routledge.

[3] Colclough, C. 2012. Education, poverty and developmentmapping their interconnections. Comparative Education. 48:2. pp135-148.

[4] IMF World Economic Outlook (WEO), October 2015. http://www.knoema.com/nwnfkne/world-gdp-ranking-2015dataand-charts.

[5] Marshall, J. 2014. Introduction to Comparative and International Education. Los Angeles: SAGE.

[6] Phillips, D. and Schweisfurth, M. 2014. $2^{\text {nd }}$ Ed. Comparative and International Education: An Introduction to Theory, Method and Practice. London: Bloomsbury.

[7] Phillips, D. 2000. Learning from Elsewhere in Education: Some perennial problems revisited with reference to British interest in Germany. Comparative Education. 36:3.pp-297-307.

[8] Steiner-Khamsi, G. 2014. Cross-national policy borrowing: understanding reception and translation. Asia Pacific Journal of Education. 34:2. Pp. 153-167.

[9] Siddiqui, K. 1996. Towards Good Governance: Fifty Unpleasant Essays. Dhaka: The University Press Limited.

[10] Ministry of Education. 2001. Notice of the issuance of 'Basic Education Curriculum Reform Programme (Trial)' by the Ministry of Education (in Chinese). http://www.gov.cn/gongbao/content/2002/content_61386.htm

[11] King, K. 2014. China's engagement with the post-2015 development agenda: The case of Education and training. International Journal of Educational Development. 39. pp 70-77.

[12] Tan, C. 2015. Education policy borrowing and cultural scripts for teaching in China. Comparative Education. 51:2. Pp. 196-211. http://www.reports.weforum.org/human-capital-report2015/rankings/

[13] Phillips, D. and Ochs, K. 2004. Researching Policy Borrowing: Some Methodological Challenges in Comparative Education. British Educational Research Journal. 30:6. pp 773-784. 
[14] Phillips, D. and Ochs, K. 2003. Processes of Policy Borrowing in Education: Some Explanatory and Analytical Devices. Comparative Education. 39:4. pp 451-461.

[15] Ochs, K. and Phillips, D. 2002. Comparative Studies and 'CrossNational Attraction' in Education: A typology for the analysis of English interest in educational policy and provision in Germany. Educational Studies. 28:4. pp 325-339.

[16] Nguyen, P.M., Elliot, J.G., Terlouw, C. and Pilot, A. 2009. Neocolonialism in education: Cooperative Learning in an Asian context. Comparative Education. 45:1, pp 109-130.

[17] Schweisfurth, M. 2011. Learner-centred education in developing country contexts: From solution to problem? International Journal of Educational Development. 31. pp 425-432.

[18] Gu, Q. and Schweisfurth, M. 2006. Who Adapts? Beyond Cultural Models of 'the' Chinese Learner. Language, Culture and Curriculum. 19:1, pp 74-89.
[19] Little, A. 2003. Motivating Learning and the Development of Human Capital. Compare. 33:4. pp 437-452.

[20] Ministry of Education, Education Statistics 2005, Government of the People's Republic of Bangladesh, 5 July, 2007. http://www.moedu.gov.bd/edu_statistics.php

[21] National Education Policy 2010, Ministry of Education, People's Republic of Bangladesh.

[22] Schweisfurth, M. 2015. Learner-centred pedagogy: Towards a post-2015 agenda for teaching and learning. International Journal of Educational Development. 40. pp 259-266

[23] http://www.cebr.com/reports/world-economic-league-table-2015/.

[24] http://hdr.undp.org/en/composite/IHDI.

[25] http://www.kpmg.de/docs/Education-in-China-201011.pdf.

[26] Bangladesh Constitution. 